\title{
LA PLUMA / EL BOLÍGRAFO / LA MÁQUINA DE ESCRIBIR / LA COMPUTADORA. REFLEXIONES SOBRE LOS INTELECTUALES Y EL PODER EN EL PERÚ
}

\author{
EMILIO ROSARIO PACAHUALA \\ UNIVERSIDAD NACIONAL MAYOR DE SAN MARCOS \\ emiliorosariog81@hotmail.com
}

\section{RESUMEN}

La relación entre los intelectuales y el poder ha sido de forma continua. Podemos apreciar intelectuales que hipotecaban su pluma en favor de un gobierno y se encontraban mordazmente en contra de otro para alcanzar los privilegios que significaba ello. Nuestro objetivo es realizar un breve devenir del intelectual haciendo hincapié en el caso peruano. Para ello utilizaremos los principales autores que han investigado sobre dicho tema.

Palabras Clave: Historia, historia universal, política, cultura, intelectuales.

\begin{abstract}
The relationship between intellectuals and power has been continuously. We see intellectuals who mortgaged his pen in favor of a government and were scathingly against another for the privileges which meant it. Our goal is to make a brief evolution of intellectual emphasizing the Peruvian case. We will use the main authors who have researched on this subject.
\end{abstract}

KeYwoRDs: History, world history, politics, culture, intellectuals.

\section{INTRODUCCIÓN}

¿Qué es un intelectual?, una interrogante que a lo largo de los años ha sido respondida de diversas maneras. Podemos mencionar como primera propuesta la premisa aportada por el Diccionario de la Real Academia Española (DRAE) la cual señala que el intelectual es la persona «dedicada al cultivo de la ciencia y las letras».

Otro concepto propuesto es el realizado por Sergio Bagú: «[...] el intelectual elabora un conocimiento nuevo, para lo cual traduce y resume el conocimiento que le rodea y. además, lo interpreta y enriquece, inyectando siempre en su sentido último esa cuota biográfica presente en todo lo humano, pero muy decisiva en su obra 
intelectual» (Bagu 1971: 68). Como apreciamos su apreciación es mucho más completa si la comparamos con la emitida por el DRAE y, además, está a la par con la concepción común que maneja la comunidad científica; sin embargo, esta deja aún importantes vacíos a ser respondidos debido a que solo vincula a los intelectuales con el plano académico, pero no insinúa siquiera su papel en la sociedad.

A nuestro parecer, los verdaderos intelectuales deben trascender mucho más allá de una creación de tipo cultural. Los intelectuales son hombres, mujeres y homosexuales de su tiempo que representan una corriente de opinión, su palabra genera debate en la sociedad. Ellos se encuentran partícipes en los ámbitos políticos nacionales e internacionales e incluso tienen un objetivo común: «decir la verdad y revelar el engaño» (Chomsky 1969).

Bajo esa idea existen matices distintos que exploran al intelectual como ente activo de la sociedad, por ejemplo Antonio Gramsci señala que la función central de lo que llama el «intelectual orgánico» es dar una conciencia de clase al grupo que pertenece, de esta forma los grupos subalternos tendrán la capacidad de discernir sobre su realidad y poder actuar sobre ella (Gramsci 1967). Misión similar es sugerida por Norberto Bobbio quien propugna que el intelectual debe buscar homogenizar el conocimiento de la población de esta manera derribará los muros que dividen a los pobres y quienes ostenten el poder, este proceso lo denomina «política de la cultura» (Bobbio 1998), es por ello que los intelectuales no pueden ser personas pasivas, ellos deben convertirse en lo que Walter Benjamin «escritores operantes ${ }^{1} »$. Pero Benjamin va mucho más allá - a comparación de sus pares académicos- ya que no solo debe tener en cuenta la importantísima misión asignada al intelectual, además debemos abordar las condiciones en las que realizará su tarea de esta manera distinguiremos los pro y contra que se presentaron para su hacedero, entre otras palabras contextualizan sus hechos y palabras. En lo que coinciden todos los autores anteriormente mencionados es que los verdaderos intelectuales deben criticar y combatir al sistema dominante, en favor de los dominados (Bourdieadu 2003).

El objetivo del presente ensayo es hacer un devenir del término intelectual para conocer cómo este tipo de entes sociales han evolucionado su accionar con el paso del tiempo haciendo hincapié en el caso peruano.

\section{LOS «INTELECTUALES》 DE OCCIDENTE}

En la actualidad se vincula al intelectual con los hombres de las letras, en tanto que el científico es el dedicado a las ciencias e ingenierías. Esta concepción que se respira actualmente en el ambiente nacional es errado, pero es poco combatido por las instituciones universitarias - tanto públicas como privadas- por el contrario su silencio afianza esa visión. Para conocer cómo se forjó esta diferencia tenemos que recurrir a los orígenes.

Los intelectuales de la Edad Antigua cultivaron destrezas y habilidades singulares frente a sus contemporáneos, empero el ser innovadores no significaba que estuvieran libres de las necesidades humanas las cuales debían ser satisfechas, por lo menos las primarias (alimentación y vestido); de esta manera y sin abandonar sus buenas artes buscaron vivir como «agentes personales, consejeros, tutores o amigos de los soberanos» (Shils 1974: 26), por ejemplo uno de los más grandes filósofos de la Grecia antigua, Aristóteles se convirtió en maestro de Alejandro Magno lo que le permitió tener un soporte económico para cumplir con las necesidades mencionadas pero que a la vez permitian tener tiempo libre para desarrollar su capacidad creadora, quizás podamos hacer de excepción a la regla a quienes poseían sus propios recursos. Lo interesante del caso era que la gran mayoría de intelectuales estuvo vinculada de una u otra manera al poder de los gobiernos.

En la Edad Media, la relación entre los intelectuales con los monarcas y señores feudales no fue tan intensa lo que generaba que las fuerzas productivas dominantes de la sociedad no estén a dispo- 
sición, sin embargo no estuvieron del todo aislados, los intelectuales buscaron cobijo a costa de la iglesia y quienes no lo conseguían se dirigían a las ciudades a buscar suerte lo que les permitió sobrevivir (Le Goff 1999). En la Edad Moderna la necesidad de los burgueses por tomar el poder político forjó su acercamiento implícito con la intelectualidad. La burguesía tenía que disponer de personas que escriban sobre el sistema que estaban constituyendo y liquidar el modelo imperante un ejemplo es la crítica de la ilustración al absolutismo. No es coincidencia que las revoluciones burguesas de los siglos XVII y XVIII tuvieran previamente grandes revoluciones intelectuales, no por ello estaremos hablando de Thomas Jefferson, Diderot, Juan Jacobo Rousseau entre otros, grandes referentes de las ciencias políticas modernas y guías matrices para legitimar la violencia en contra del Ancien Regime.

Una vez derribado los monarcas despóticos los intelectuales eran vistos no como una necesidad sino como una mercancía de lujo, muchas veces innecesarias ya que habían cumplido su tarea. Esta nueva situación forzó a que la mayoría de ellos, por supervivencia «[...] se especializan en los ámbitos más lucrativos de la actividad literaria: la redacción de artículos enciclopédicos, las traducciones, la edición de obras completas, la redacción de libros de consulta prácticos, de manuales y de literatura popular» Charle (2000: 12). Esto es en respuesta a que en el mundo estaba naciendo el mercado de la lectura: volantes, panfletos y periódicos comenzaron a circular, convirtiéndose en el espacio perfecto para que pueden ser colocado los escritos, discursos y poemas. Si los intelectuales antiguamente personalizan y particularizan su saber a los futuros reyes, ahora este se modificará no solo por quienes sabían leer sino por quienes podían escuchar. Entrará con fuerza otro viejo actor pero renovado por las condiciones materiales: "el rumor», un elemento que ha amenazado a la verdad y que hasta ahora es un hueso duro de roer, para combatirlo, serán los debates públicos y manifiestos las mejores armas, por tanto los intelectuales tenían que implementar otra característica (aunque accesoria), la oratoria, elemento que en la actualidad ha sido privatizado por los políticos de profesión.

Con el nacimiento del Estado moderno se tuvo una nueva necesidad construir la organización del mismo, para ello necesitaría nuevamente de los intelectuales para tener validez existencial; por tanto el gran mecenas entre el siglo XVIII y el XIX será el leviatán gubernativo.

\section{Los INTElectuales Y El PODER Político: De LA Colonia Al Siglo XIX}

El desarrollo del capitalismo y su expansión condujo a la profesionalización y tecnificación del mundo, de pronto la educación sería impartida a gran escala ¿ahora todos serán intelectuales, ya que acceden al conocimiento? ¿Bastaba ser intelectual con solo saber leer y escribir como en la Edad Antigua, Media y Moderna? Al parecer no, esto requería mucho más que solo ser alfabeto los requisitos para ser catalogado intelectual habrían de aumentar, tenía que existir creatividad e innovación para distinguirse, entre una multitud cada vez más letrada, pero además poseer prestigio público, término nada nuevo; que mantiene hasta ahora su vigencia.

A fines del siglo XIX en Francia, nace oficialmente el término intelectual; ello en el marco del enjuiciamiento al general Alfred Dreyfus quien fue acusado de venderle secretos bélicos al máximo rival de Francia, nos referimos a Prusia, sin embargo, no existía una prueba contundente para acusarlo, dividiéndose la opinión pública, entre quienes estaba a favor de su encarcelamiento y degradación militar y los que estaban en contra al no encontrarse elementos contundentes para su culpabilidad, entre este último grupo se encontraba Emilio Zola quien defiende a Dreyfus mediante un manifiesto público titulado De los intelectuales. Pero este pronunciamiento no solo se conformó en constituir una palabra a la deriva ello pone de manifiesto que para ser tildado intelectual se necesitaba «[...] elevarse sobre las fronteras y preocupaciones profesionales, a desprenderse de los criterios de la especialización del saber y de género literario o artístico, para comprometerse en cuestiones a la verdad y la justicia» (Altamirano 2012: 47). Sin embargo, el mundo no es eurocéntrico por tanto su desarrollo es heterogéneo, la palabra intelectual de la misma manera tendría significados en función a su tiempo y espacio. 
En octubre de 1492 comenzaría el encuentro de los dos mundos, en nuestra América se forjó lo que Ángel Rama llamaría la «ciudad letrada», el símbolo de cemento y concreto que constituyó el dominio europeo, este espacio llevo las tradiciones y costumbres del viejo continente al nuevo mundo, también sería el lugar idóneo para regular la vida de los indígenas a imagen y semejanza de los dominadores:

«[...] en tanto género literario, la evolución del sermón corrió pareja en el Perú a la campaña de homogenización lingüística. La publicación de piezas oratorias se vio nutrida por la de diccionarios y gramáticas. Sus contenidos sirvieron de base no solo para la transmisión oral de la cultura cristiana. Los sermones fueron igualmente esenciales para la alfabetización y su dominio se convirtió en un símbolo de prestigio en las ciudades. Las grandes piezas retóricas eran escuchadas en las catedrales y en las grandes parroquias; en palacio, en las iglesias del clero regular y en los claustros universitarios» (Mazín 2008: 62).

En comparación de lo que pasaba en Europa, en donde la formación de burguesías gestaría orgánicamente grupos intelectuales que pugnaría con la vieja guardia religiosa ${ }_{2}$ como relatamos en los párrafos anteriores, aquí los que promoverían y monopolizarían la educación sería la iglesia católica, por ende, cuestionar al «viejo estado» sería difícil, tendrían que pasar casi 300 años para que ello se realice.

Como es harto conocido, a fines del siglo XVII el poder español empezó a decaer estrepitosamente, la era de Felipe II que habría de significar grandeza en el Atlántico para los españoles, ahora se convertía en un recuerdo en los palacios hispánicos; serían ingleses y franceses quienes llegarían a puertos sudamericanos para comenzar el proceso de comercialización. El mercantilismo decaería frente al avance implacable del librecambismo. El golpe de gracia fue la independencia de los Países Bajos (Holanda y Bélgica) dejando a España huérfano de la actividad manufacturera, tan solo le quedaba vivir de los impuestos comerciales a consecuencia de las reformas borbónicas (siglo XVIII).

A fines del siglo XVIII los intelectuales del virreinato peruano adquirieron un perfil propio y comenzó a establecer vínculos con el poder al más alto nivel (tal vez imitando el ejemplo de sus pares europeos). Esta relación comenzó con los ilustrados criollos y el virrey, ante el cual pusieron a su servicio exclusivo los primeros en favor del segundo, una de las revistas de mayor influencia académica durante la colonia nos referimos al Mercurio Peruano. Entre los personajes que dirigieron dicha revista destacará con luz propia Hipólito Unanue, quien se declaró defensor del sistema regio, empero cuando el gobierno hispánico decayó se enrolaría en las filas del gobierno republicano con San Martín, convirtiéndose en un «letrado patriota» (Myers 2008: 121-143). Estos letrados patriotas serán los encargados de escribir versos y composiciones a los noveles países, redactarán discursos y vivas a los héroes de la Independencia además de ser los encargados de mitificar las fiestas nacionales.

Una vez lograda la expulsión de España se constituían las repúblicas cada una de ellas con diferentes destinos: «La independencia no solo significó la separación respecto de España sino la búsqueda de un nuevo tipo de legitimidad, jurídico-democrática. De allí la enorme importancia de la instrumentación jurídica de la independencia, de los congresos, las constituciones y las leyes que acompañaron» (Pérez 2008: 173), es por ello que los juristas jugaron un rol como los grandes ideólogos de los nuevos estados; junto con los sacerdotes. Sin embargo existieron facciones que deseaban la expansión de la ciudadanía y que esta no solo incluya a los criollos también a las masas indígenas. En ese debate se forjan dos visiones: conservadores versus liberales, siendo estos últimos los vencedores.

A mediados de la centuria decimonónica los intelectuales no habían constituido espacios propios, para la divulgación del conocimiento dado que los gobiernos caudillistas poco o nada hicieron por promoverlos. Empero esta habría de cambiar con el régimen de Castilla, quien tuvo la fuerza gracias a los ingentes recursos guaneros y la inversión pública lo que permitió al leviatán gubernativo forjar 
su propia burocracia e intelectualidad. Las revistas académicas y la creación de colegios técnicos fueron muestra de ello. Sin embargo, la guerra del Pacífico tiró por la borda todo proyecto e iniciativa por parte del gobierno central, los pocos privilegiados que gozaron del conocimiento antes de 1879 tendrían que responder sobre las causas de la no victoria frente a Chile, justificando -como el caso de Riva-Agüero- la inacción e incapacidad de la clase dominante. El papel que jugó la intelectualidad peruana a fines del siglo XIX es reflejado por la escritora Mercedes Cabello Carbonero quien señalaba que: «[...] las letras desempeñan el rol más importante en la civilización de un pueblo, combatiendo las preocupaciones absurdas que vician y adulteran la sana moral y despertando el alma del adormecimiento $o$ anonadamiento, la levanta de la postración» (Cabello 1892: 7). Se tendría que esperar unas décadas más para constituir los cuerpos institucionales profesionales e intelectuales.

En la etapa de la posguerra, los intelectuales buscaron más que nunca identificarse con el poder político. Si antes de 1879 lo hacían de manera casi clandestina, ahora sentaron una presencia mucho mayor por ejemplo Ricardo Palma con Nicolás de Piérola; Clorinda Matto de Turner con Andrés Avelino Cáceres, por citar algunos ejemplos.

Si algo enseñó esta etapa es que se necesitaban de personas que legitimen los gobiernos con versos y discursos, quizás por ello se resaltó a los hombres de las letras dejando relegados a los de las ciencias, quienes gracias a los avances del siglo XX y su falta de popularidad por parte de los políticos de profesión comenzarían a monopolizar el término científico. Los gobiernos en general son los que más han necesitado atraer a los intelectuales, como un modo de legitimar su mandato y dar la apariencia de consenso con sectores civiles a la vez que disfrazar sus proyectos bajo una fachada académica. De esta manera, las gestiones gubernamentales fueron las más generosos con los sectores académicos, al menos con los que comulgan bajo su órbita. Y esto lo hacen a través de cargos políticos o administrativos: museos, bibliotecas, institutos, centros de investigación, fondos editoriales, entre otros.

No es coincidencia que la generación del centenario hayan articulado su quehacer en función a criticar al poder dominante con el fin de ellos convertirse en los dirigentes nacionales y acceder a la burocracia estatal. En todos estos casos los intelectuales necesitan de cierta dosis de influencia en la administración pública para llevar a cabo sus proyectos, de modo que estos no se queden en el papel. En su propósito no dudaron en acercarse a gobiernos de izquierda o derecha e incluso autoritarios.

\section{LA INTELECTUALIDAD DURANTE EL SIGLO XX Y PRINCIPIOS DEL XXI}

Habrían de surgir nuevos sectores sociales producto de la transformación económica después de la guerra del Pacífico. Ellos querían ofrecer a sus hijos las mismas ventajas que gozaban las viejas clases dominantes. Esta ampliación del desarrollo intelectual, a medio y largo plazo, condujo al surgimiento de nuevos productos culturales: revistas, teatros, cafés entre otros.

Como señalamos la Edad Contemporánea alejó al Estado de los intelectuales como paliativo en un primer momento se crearon «ayudas gubernamentales para los hombres de letras», pero con el paso del tiempo estos fueron desapareciendo «[...] por lucrativos empleos en la carrera de funcionarios de la administración civil» (Shils 1974: 39). La política para los intelectuales se volvió en un medio idóneo para satisfacer sus necesidades y crear conocimiento, hombres como José Santos Chocano, Enrique López Albújar y Abraham Valdelomar tendrán que asumir conducciones y militancias en los partidos políticos. Existieron otros que al no optar por ello terminaron en sendas desgracias «José Arnaldo Márquez paseó por toda América la desesperación de su cabeza coronada de espinas; Carlos Augusto Salaverry sumó en un rincón de París la miseria a que le condenó el olvido de los suyos; Clemente Althaus sintió estallar en locura final el cargo que se le hizo de no haber llegado a ser más que un poeta» (Chocano 1940: 141).

Este abandono del Estado como mecenas, hacia el sector «apolítico» de la intelectualidad es explicado por Carlos Prince: 
«[...] estos dos hechos prueban evidentemente que algunos gobierno de Sudamérica preceden en este sentido, con poco juicio y equidad en premio a los escritores, dando a unos con demasiado desprendimiento, y negando a otros lo necesario, sin tener en cuenta que estos, más que aquellos, son tal vez más acreedores para ser protegidos preferentemente. Hoy, aunque el escritor tenga los padrinos más influyentes, y aunque sus producciones sean del mayor interés histórico para el país, no consigue que el gobierno preste apoyo alguno, a pesar de que el Estado tiene el deber de impulsar y fomentar las letras nacionales».

Continúa explicando el literato:

«[...] no hay recuerdo de que en estos últimos tiempos se haya dado a luz ninguna obra literaria o histórica patrocinada por el gobierno del Perú, y cuando algún autor solicita este favor se le contesta que el erario no tiene fondos disponibles para emprender estos gastos. $Y$, sin embargo, no han faltado fondos para sostener periódicos cotidianos y hebdomadarios dedicados a ensalzar todos los actos de los mandatarios, consejeros y demás autoridades [...] tampoco han faltado fondos para emprender y costear obras y trabajos innecesarios, que ha pagado al gobierno con el único propósito de favorecer a paniaguados predilectos» Prince (1913: 5).

No podemos pensar que solo en la capital apareció la intelectualidad. En el interior del país existió una nutrida gama de pensadores que incluso forjaron revistas como el Boletín Titikaka o la formación del «grupo norte» en donde destaca la figura de César Vallejo.

La ideologización fue un tema que comenzó a estar impregnado en la población a partir de la década de 1930. Los intelectuales no estarían divorciados de este proceso por ejemplo José de la RivaAgüero se vinculó al fascismo, Luís Alberto Sánchez se unió a las filas del aprismo, la derecha tendría a Víctor Andrés Belaúnde como uno de sus baluartes; en tanto la izquierda tuvo entre sus allegados a Javier Heraud, Pablo Macera, Luis Guillermo Lumbreras, Alberto Flores Galindo entre otros, curiosamente en este último caso es la intelectualidad de izquierda la que sufrirá el colapso de la caída del muro de Berlín (1989) haciendo añicos sus sueños de un cambio de sistema, muchos tendrán que ir al ostracismo en donde hasta la fecha preparan su reingreso triunfal a la sociedad a ser como siempre lo han sido, actores primordiales.

La intelectualidad en el Perú tuvo presencia en todos los ámbitos, incluido en el conflicto interno, en donde ambos bandos, tanto el gobierno como Sendero Luminoso apertrecharon a sus «ideólogos» para combatir en las tribunas y los escritos sosteniendo encarnizados enfrentamientos reflejados en panfletos y artículos periodísticos principalmente:

«[...] nunca hubo movimiento armado en América Latina que diera tal importancia al componente intelectual de su propuesta y a la condición de intelectual de su jefe máximo, el doctor Abimael Guzmán, entronizado en afiches y pinturas con todos los atributos del intelectual: anteojos, terno y libro bajo el brazo. Los intelectuales mestizo provenientes mayoritariamente de universidades públicas y ciudades medianas de los Andes, que constituían buena parte de la dirección del PCP-SL reclamaban todo el poder político, pero también -y de manera excluyente- toda la legitimidad intelectual. El resto éramos pre científicos y/o siniestros agentes del viejo Estado» (Degregori 2010: 41).

Ya en el siglo XXI, a pesar de las dificultades los intelectuales sobrevivieron pero habrá de enfrentar otros peligros. Además de la atomización de las profesiones, también la mercantilización de todos los objetos incluidos los culturales: «[...] la cultura dejaba de ser ámbito de razonamiento crítico $y$ se convierta en uno de mero consumo ideológico, a medida que la masificación de los medios de comunicación - edición, prensa y radio- tendía a destruir a los públicos verdaderamente independientes» (Anderson 2008: 130). Esta situación pone en relieve que no podemos hablar de «intelectual» sino de intelectuales que se amoldan en función a las circunstancias y en el lugar en donde desean posicionarse, este aspecto es clasificado por el literato peruano Mauro Mamani: «intelectuales absorbidos (ponen su pluma al ser- 
vicio del mejor postor), intelectuales totales (líderes de opinión académico), intelectuales indiferentes (dedicados a sus investigaciones) y los intelectuales coherentes (aquellos que mantiene un solo pensamiento teórico y práctico)». ${ }^{2}$

Dependerá de nuevas estrategias que permitirán al intelectual mantener vigente en el tiempo y espacio.

\section{CONCLUSIONES}

Coincidimos con las conclusiones realizadas por el argentino Carlos Altamirano al definir al intelectual en la actualidad:
«[...] en primer lugar, que el intelectual no tiene una sola audiencia, un solo público, y que los criterios de los propios intelectuales para juzgar la relevancia de sus pares no son los mismos que rigen para que ellos que, si bien se interesan por las Ideas y discuten las definiciones sobre la marcha del mundo que producen los intelectuales, no giran en la órbita de la vida intelectual. En segundo término, que el concento de intelectual resulta irreductible al de una categoría socio profesional, pues con ese término se agrupa y se identifica a un abigarrado conjunto de personas que poseen conocimientos especializados y aptitudes cultivadas en diferentes ámbitos de expresión simbólica y que proceden de diversas profe- siones» Altamirano (2008: 14).

En el Perú aún falta romper ese esquema que el intelectual solo es aquel que se dedica a las cuestiones académicas, solo con su participación activa podremos elevar el nivel a nuestra política o tal vez hacerla mucho más constructiva ya que debatiremos ideas y proyectos, elementos en que estábamos huérfanos.

2 Mauro Mamani. <www.intelectuales.org.pe>. En: Identidades. Suplemento cultural de El Peruano. 2002 


\section{BiBLIOGRAFÍA}

ALTAMIRANO, Carlos

2012 La intelectualidad en América Latina. En: Mejía Navarrete (ed.), América Latina en debate. Sociedad, conocimiento e intelectualidad. Lima: Universidad Ricardo Palma.

2008 Historia de los intelectuales en Latinoamérica. Buenos Aires: Katz editores.

ANDERSON, Perry

2008 Spectrum. De la derecha a la izquierda en el mundo de las ideas. Madrid: Ediciones Akal.

BAGÚ, Sergio

1978 Tiempo, realidad social y conocimiento. Madrid: Siglo XXI editores.

BENJAMÍN, Walter

1998 Poesía y capitalismo. Iluminaciones II. Santa Fe: Editorial Taurus.

BOBBIO, Norberto

1998 La duda y la elección, intelectuales y poder en la sociedad contemporánea. Barcelona: Ediciones Paidos.

BOURDIEU, Pierre

2003 Intelectuales, política y poder. Buenos Aires: Eudeba 2da edición.

CABELLO DE CARBONERA, Mercedes

1892 La novela moderna. Estudio filosófico. Lima: Tipolitografía Bacigalupo \& Co.

CHARLE, Christophe

2000 Los intelectuales en el siglo XIX. Precursores del pensamiento moderno. Madrid: Siglo Veintiuno editores.

CHOCANO, José Santos

1940 Las mil y una aventuras. Santiago de Chile: Editorial Nacimiento.

CHOMSKY, Noam

1969 La responsabilidad de los intelectuales. Buenos Aires: Editorial Galeno.

DEGREGORI, Carlos Iván

2010 Qué difícil es ser Dios. El Partido Comunista del Perú- Sendero Luminoso y el conflicto armado interno en el Perú (1980-1999). Lima: Instituto de Estudios Peruanos.

GRAMSCI, Antonio

1967 La formación de los intelectuales. México D. F.: Editorial Grijalbo.

MAZÍN, Oscar

2008 «Gente de saber en los virreinatos de Hispanoamérica». En: Carlos Jorge Myers (ed.) El letrado patriota: los hombres de letras hispanoamericanos en la encrucijada del colapso del imperio español en América. Carlos Altamirano. Historia de los intelectuales en Latinoamérica. Buenos Aires: Katz editores.

LE GOFF, Jacques

1999 Los intelectuales en la Edad Media. Barcelona: Editorial Gedisa.

PRINCE, Carlos

1913 Mi estancia de medio siglo en Lima (1862-1912). Lima: Imprento en la casa del autor.

SHILS, Edward

1974 Los intelectuales y el poder. Buenos Aires: Ediciones Tres Tiempos. 